\title{
Effects of Spironolactone About Vascular Inflammation on a Metabolic Syndrome Model
}

\author{
Nicolas F Renna ${ }^{1,3^{*}}$, Rodrigo D Garcia ${ }^{1}$, Jesica M Ramirez ${ }^{2}$ and Roberto M Miatello ${ }^{1}$ \\ ${ }^{1}$ Department of Pathology, School of Medicine, National University of Cuyo, IMBECU-CONICET, Argentina \\ ${ }^{2}$ Genetics Institute, School of Medicine, National University of Cuyo, Argentina \\ ${ }^{3}$ Centro Integrativo de Biología y Química Aplicada (CIBQA), Universidad Bernardo OHiggins, Santiago, Chile
}

Submission: June 13, 2019; Published: June 20, 2019

*Corresponding author: Nicolás Federico Renna, Facultad de Ciencias Médicas, Universidad Nacional de Cuyo, Av. Libertador 80. Centro Universitario 5500- Mendoza, Argentina

\begin{abstract}
Background: Aldosterone (A) has pro-oxidative, pro-growth and pro-inflammatory effects in different tissues. We have previously demonstrated that in vascular inflammation different cytokines as NF-kB and VCAM-1 were present and generated a proinflammatory microenvironment that supports this cardiovascular remodeling. We proposed to evaluate the effects of spironolactone (S) antagonist mineralocorticoid receptor (MR) about vascular remodeling in metabolic syndrome model.

Methods: Male WKY and SHR were separated into five groups: Control, FFR: WKY rats receiving a $10 \%(\mathrm{w} / \mathrm{v})$ fructose solution during all 12 weeks, SHR, FFHR: SHR receiving a 10\% (w/v) fructose solution during all 12 weeks and FFHR+S: (5 mg/kg per day for 6 weeks) (n=8 each group). Metabolic variables and systolic blood pressure were measured. The oxidative stress status, cardiac and vascular remodeling were also evaluated. To assess different cytokine, immunostaining and chemiluminicent techniques were used.
\end{abstract}

Results: The FFHR experimental model presents metabolic syndrome criteria, vascular and cardiac remodeling, vascular inflammation due to increased expression of NF-kB, VCAM-1 and pro-atherogenic cytokines. Spironolactone was able to reverse total or partiality the variables studied

Conclusions: The present study demonstrates that vascular inflammation and remodeling in FFHR could be attenuated by MR antagonism through processes associated with reduced vascular oxidative stress and cytokines responses.

Keywords: Fructose-fed hypertensive rats; Metabolic syndrome; Hypertension; Oxidative stress; Vascular inflammation; Cytokines; Cardiovascular; Hypertensive animal models; Cardiac hypertrophy; Inflammation; Extracellular matrix

Abbreviations: A: Aldosterone; S: Spironolactone; MR: Mineralocorticoid Receptor; SHRSP: Stroke-Prone Spontaneously Hypertensive Rats; EC: Endothelial Cells; TNF-alpha: Tumor Necrosis Factor-Alpha; ROS: Reactive Oxygen Species; MCP-1: Macrophage Chemotactic Protein-1; DM2: Type 2 Diabetes Mellitus; SHR: Spontaneously hypertensive rats; FFR: Fructose-Fed Rats; WKY: Wistar Kyoto; DW: Drinking Water; SBP: Systolic Blood Pressure; HOMA: Homeostasis Model Assessment; TBARS: Thiobarbituric Acid-Reactive Substances; DPI: Diphenylene Iodinium; eNOS: Endothelial Nitric Oxide Synthase; RHW: Relative Heart Weight; LV: Left Ventricle; IHC: Immunohistochemistry; CRP: C Reactive Protein; MCP-1: Monocyte Chemotactic Protein-1; MIP-3: Macrophage Inflammatory Protein-3 alpha; TIMP-1: Tissue Inhibitor of Metalloproteinase; GM-CSF: Granulocyte-Macrophage Colony-Stimulating Factor; INF- $\gamma$ : Interferon Gamma; NO: Nitric Oxide

\section{Introduction}

In vivo studies provided evidence that aldosterone contributes to the promotion of cardiovascular end-organ damage in hypertensive animal models characterized by abnormal activation of the RAAS. Indeed, MacLeod et al. [1] demonstrated that exogenous administration of aldosterone reduced the protective effect of captopril against stroke in stroke-prone spontaneously hypertensive rats (SHRSP).
Furthermore, Rocha et al. [2] observed that spironolactone markedly reduced the incidence of renal vascular lesions in saline-drinking SHRSP. Also, it has been documented that spironolactone ameliorated the cardiac hypertrophy, inflammation, and extracellular matrix production in Ang IIinduced cardiac injury [3]. 
In immune response, it has been reported that aldosterone stimulation promotes proinflammatory responses in various tissues [4,5]. In human leucocytes, MR expression has been reported in $\mathrm{CD} 34+$ hematopoietic progenitor, also in peripheral blood $\mathrm{T}$ and B lymphocytes, monocytes, and neutrophils [6]. Further, clinical studies have demonstrated that MR antagonism in cardiovascular diseases can generate a beneficial outcome in patients, due to the prevention of inflammatory damage [7].

Aldosterone plays an important role in vascular remodeling that has been attributed to BP elevation with secondary vascular consequences. However, it has recently become clear that aldosterone also has extra-renal actions. MR is expressed in vascular SMC and endothelial cells (EC) where it regulates genes involved in vascular inflammation, fibrosis and calcification [813]. Indeed, we have recently demonstrated in a mouse model with inducible, SMC-specific MR deletion, that SMC-MR directly contributes to vascular contractile function and BP elevation with aging [14].

Dafina Pruthi et al. [15], that the aldosterone enhanced to vascular remodeling in a model of SMC in vivo. Aldosterone induces vascular SMC proliferation and fibrosis after injury without effecting endothelial re-growth. Also, these effects of aldosterone are completely lost in a model of mice with the MR specifically deleted from SMC in adulthood. SMC-MR also contributes to injury-associated vascular fibrosis even without addition of exogenous aldosterone. Blockade of VEGFR1 signaling with receptor-specific antibodies also prevents aldosterone-induced SMC proliferation and vascular fibrosis after injury in vivo.

Furthermore, MR antagonism with spironolactone in a hypertension rat model reduced end-organ damage due to blockade of 17 polarization and the induction of regulatory $\mathrm{T}$ cells [16]. These studies clearly suggest that MR stimulation or antagonism plays a role not only in innate immune activation, but also in the polarization of the adaptive immune response.

One of the key mechanisms in the pathogenesis of diabetesrelated vascular dysfunction is oxidative stress. Oxidative stress is attributable to excessive production of reactive oxygen species (ROS) and inflammatory markers by tumor necrosis factor-alpha (TNF-alpha), macrophage chemotactic protein-1 (MCP-1) and other markers [17]. The inflammatory response was reported to downregulate eNOS expression and upregulate iNOS expression in rodents and increase NAD(P)H oxidase activity and vascular remodeling [18].

Preclinical and clinical studies have shown that aldosterone is positively regulated in type 2 diabetes mellitus (DM2) $[19,20]$. Aldosterone, a steroid hormone from the mineralocorticoid family, is critically involved in electrolyte balance and blood pressure control. Aldosterone actions are mediated mainly through mineralocorticoid receptors (MR) via well-characterized genomic mechanisms. In addition to long-term transcriptional effects, aldosterone has important acute or non-genomic actions in the cardiovascular system, influencing vascular reactivity and remodeling, endothelial function, inflammatory, and redox processes [21-25].

Spontaneously hypertensive rats (SHR) provide a model of genetic hypertension that allows the study of primary hypertension. The administration of carbohydrate-rich diets to rats can induce insulin resistance, hyperinsulinemia, dyslipidemia and moderate hypertension. Chronic fructose-fed rats (FFR) provide a useful experimental model for studying the interaction of the factors that shape metabolic syndrome [9]. We postulate that this dual experimental model could be appropriate for extrapolating results to human pathology [26].

Given that it has been shown that aldosterone has prooxidative, pro-growth and pro-inflammatory effects, we propose that, in the model this experimental model insulin-resistance and hypertension, aldosterone is necessary to trigger vascular inflammatory response involved to vascular remodeling present in previous experimental studies. We use spironolactone to examine their role in the activation of different molecular inflammatory cytokines, NF-kB and VCAM-1 to generate a microenvironment that supports the cardiovascular remodeling.

\section{Methods}

\section{Animals and experimental design}

All procedures were performed according to institutional guidelines for animal experimentation; the protocol was submitted and approved by the Institutional Committee for Laboratory Animal Use and Care (CICUAL) of the School of Medicine-UNCuyo № 91/2016. Thirty-day-old male Wistar Kyoto (WKY) and SHR rats were fed a standard commercial chow diet ad libitum and housed in a room under conditions of controlled temperature $\left(20^{\circ} \mathrm{C}\right)$ and humidity with a 12-hour light/dark cycle during a 12-week experimental period. Spironolactone (S) was administered to the respective groups during the last six weeks of the study.

a) I-Control (W): WKY rats receiving food and drinking water (DW) ad libitum;

b) II-SHR rats receiving food and DW ad libitum;

c) III-Fructose-fed Rats (FFR): WKY rats receiving a $10 \%(\mathrm{w} / \mathrm{v})$ fructose (Parafarm, Buenos Aires, Argentina) solution in the DW during all 12 weeks,

d) IV-Fructose-fed Hypertensive Rats (FFHR): SHR rats receiving a $10 \%(\mathrm{w} / \mathrm{v})$ fructose solution in the DW during all 12 weeks;

e) V- FFHR+V: FFHR receiving $5 \mathrm{mg} / \mathrm{kg} / \mathrm{d}$ S by intraesophageal administration.

The protocol was completed with the other 3 intermediate experimental groups $(\mathrm{WKY}+\mathrm{S}, \mathrm{FFR}+\mathrm{S}$ and $\mathrm{SHR}+\mathrm{S})$ but to 
improve the interpretation of the results and with the final objective of demonstrating our hypothesis in the experimental model FFHR, the data from these three intermediate groups, as requested by the reviewers, will be added as Appendix 1 .

At the end of the experimental period, the rats were anesthetized with sodium pentobarbital (50 mg/Kg ip), blood samples were taken and the arteries and organs were aseptically excised for measurements.

\section{Systolic blood pressure measurement}

The systolic blood pressure (SBP) was monitored indirectly in conscious, pre-warmed rats that were mildly restrained by the tail-cuff method and recorded on a Grass Model 7 polygraph (Grass Instruments Co., Quincy, MA, USA). The rats were trained in the apparatus several times before measurement.

\section{Biochemical determinations}

HOMA index and intra-peritoneal glucose tolerance test: The fasting plasma insulin was assayed using the ACS:180SE automated chemiluminescence system (Bayer, Germany). The plasma glucose levels were assayed using a commercial colorimetric method (Wiener Lab., Argentina). The homeostasis model assessment (HOMA) was used as an index to measure the degree of insulin resistance; it was calculated using the following formula: [insulin $(\mu \mathrm{U} / \mathrm{mL}) \mathrm{x}$ glucose $(\mathrm{mmol} / \mathrm{L}) / 22.5]$ [27].

Three days before the end of the experimental period, a glucose tolerance test (GTT) was performed. Rats fasted overnight were slightly anesthetized with pentobarbital, and glucose was administered ( $2 \mathrm{~g} / \mathrm{Kg} \mathrm{ip}$ ). Blood samples were taken by tail-bleeding at $0,30,60$ and 90 minutes after injection to determine the plasma glucose concentration. The total area under the curve was calculated as $\mathrm{mmol} / \mathrm{L} / 90 \mathrm{~min}$ [18].

Assessment of the lipid profile: At the end of the experimental period, blood samples were drawn from the animals after fasting for 12 hours. The total plasma cholesterol, HDL cholesterol and triglycerides were assessed using photocolorimetric enzymatic methods (Wiener Lab., Rosario, Argentina). The data are expressed in mmol/L.

\section{Oxidative stress determinations}

Measurement of plasma thiobarbituric acid-reactive substances (TBARS): To demonstrate the effect of increased oxidative stress at the vascular level, plasma lipid peroxidation was assessed by determining the TBARS concentration. This assay is based on the reaction between plasma malondialdehyde, a product of lipid peroxidation, and thiobarbituric acid, as has been previously described [28]. No correction for sample protein content was necessary because of the nature of sample [29].

Measurement of vascular NAD(P)H-oxidase activity: The lucigenin-derived chemiluminescence assay was used to determine the NAD(P)H-oxidase activity in a segment of the thoracic aorta, as previously described [28]. To assess NAD(P)
H-oxidase activity, NADPH (500 $\mu \mathrm{mol} / \mathrm{L})$ was added and chemiluminescence was immediately measured in a liquid scintillation counter (LKB Wallac Model 1219 Rack-Beta Scintillation Counter, Finland) set in the out-of-coincidence mode. Time-adjusted and normalized-to-tissue-weight scintillation counters were used for the calculations. The measurements were repeated in the absence and presence of diphenylene iodinium (DPI) (10-6 mol/L), which inhibits flavincontaining enzymes, including NAD(P)H oxidase [30,31].

eNOS activity in homogenates of cardiac and arterial tissue: The activity of $\mathrm{Ca} 2+/$ calmodulin-dependent endothelial nitric oxide synthase, (eNOS) was measured in mesenteric artery homogenates and in left-ventricle cardiac tissue based on the conversion of $\mathrm{L}-[3 \mathrm{H}]$ arginine into $\mathrm{L}-[3 \mathrm{H}]$ citruline. The values were corrected according to the protein contents in the homogenates (Bradford method) and the incubation time, and the results are expressed as $\mathrm{dpm} / \mathrm{mg}$ protein $/ \mathrm{min}$. The material obtained from each animal was processed independently [32].

Relative heart weight: To evaluate cardiac hypertrophy, we measured the relative heart weight (RHW). Briefly, the heart was separated from the great vessels, placed in a buffered saline solution (PBS), blotted with tissue paper to remove the blood, and weighed. The total heart weight was corrected according to the ratio between the heart weight (milligrams) and 100 grams of the total body weight before sacrifice.

Tissue preservation: Tissue samples for histopathology were processed as has been previously reported [22]. Samples from all rats were used for these observations. Anesthetized animals were briefly perfused with PBS (298 mOsmol/Kg H2O, $\mathrm{pH} 7.40,4^{\circ} \mathrm{C}$ ) to remove the blood. The mesenteric arteries were perfused in vivo with the same solution through the mesenteric artery for $5 \mathrm{~min}$. For the histological studies, the arteries were also perfused with a $4 \%$ paraformaldehyde solution for 10 min and fixed in paraffin. Five-micron-thick tissue slices were transversely cut across the mesenteric tissue on a microstate (Microm HM, Germany) and processed for histological studies. A similar procedure was applied for heart tissue preservation by aortic retrograde perfusion.

Quantitative Histomorphometry to determine cardiac hypertrophy: Histomorphological analyses were conducted on slices from the outer (free) wall of the left ventricle (LV) of the heart. Estimations of the cardiomyocyte area were made from sections stained with Masson trichrome solution. Areas with transverse sections of myofibers were selected. The contour of the fibers was then drawn manually. The total myocardiocyte area was expressed in square micrometers $(\mu \mathrm{m} 2)$.

Arterial structure: Changes in the structure of the arterial walls were assessed by measuring the medial layer of the mesenteric arteries. The slices were dyed and examined as has been previously described [30]. Non-transverse sectioned arteries were excluded from the investigation. The lumen-to- 
media ratio (i.e., the ratio of the internal diameter to the medial thickness) (L/M) was then calculated. Fifty slices from each animal were processed and analyzed to obtain an average value for each rat. The average values were then used for the final analysis.

SDS-PAGE and Immunoblot Analysis: The mesenteric tissue from each rat was washed in PBS, and the proteins were extracted in cold $20 \mathrm{mM}$ Tris- $\mathrm{HCl}, \mathrm{pH} 7.4,150 \mathrm{mM} \mathrm{NaCl}, 10 \%$ glycerol, 1\% Triton X-100, and a protease inhibitor mixture (P2714, Sigma). After sonication for $15 \mathrm{~s}$ (3 times with 10-s intervals) and extraction for $30 \mathrm{~min}$ at $4^{\circ} \mathrm{C}$, the sample extracts were clarified by centrifugation at $14,000 \mathrm{x}$ f for $20 \mathrm{~min}$ and used immediately or stored at $-20^{\circ} \mathrm{C}$. The proteins were separated on $10 \%$ polyacrylamide slab gels and transferred to $0.22-\mu \mathrm{m}$ nitrocellulose membranes (GE, Germany).

Nonspecific reactivity was blocked by incubation for $1 \mathrm{~h}$ at room temperature in 5\% non-fat dry milk dissolved in washing buffer (PBS, pH 7.6, 0.2\% Tween 20). The blots were incubated with anti-p65 and anti-VCAM-1 antibodies $(0.2 \mu \mathrm{g} / \mathrm{mL}$ in blocking solution) for $60 \mathrm{~min}$ at room temperature. Horseradish peroxidase-conjugated goat anti-rabbit-IgG and swine antigoat-IgG dissolved in blocking buffer were used as secondary antibodies $(0.25 \mu \mathrm{g} / \mathrm{mL}, 45 \mathrm{~min}$ at room temperature). Excess first and second antibodies were removed by washing 5 times for 5 min in blocking solution. Detection was accomplished with an enhanced chemiluminescence system (ABC, Dako System) and subsequent exposure to Kodak X-AR film (Eastman Kodak) for $5-30$ s.

\section{Immunohistochemistry and digital confocal micros- copy (IHC)}

Detection of transcription factors (WB): A rabbit antibody against the C-terminus of rat NF-kB p65 subunit [Rel

Table 1: Metabolic and cardiovascular variables

\begin{tabular}{|c|c|c|c|c|c|}
\hline Variable & WKY & FFR & SHR & FFHR & FFHR+S \\
\hline Fasting glucose $(\mathrm{mmol} / \mathrm{L})$ & $4.88 \pm 0.1$ & $6.44 \pm 0.2^{*}$ & $5.0 \pm 0.2$ & $6.5 \pm 0.2^{* \wedge}$ & $5.5 \pm 0.1^{*}$ \\
\hline Fasting triglycerides $(\mathrm{mmol} / \mathrm{L})$ & $0.8 \pm 0.0$ & $1.9 \pm 0.0^{*} \#$ & $1.0 \pm 0.0$ & $1.9 \pm 0.1^{*} \#$ & $1.7 \pm 0.2^{*}$ \\
\hline HOMA ( $\mu \mathrm{U} / \mathrm{mL}$ insulin $\mathrm{x}$ mmol/L glucose) $/ 22.5$ & $4.00 \pm 0.2$ & $11.0 \pm 0.1 * \#$ & $7.1 \pm 0.15^{*}$ & $15.1 \pm 0.5^{*} \#^{\wedge}$ & $10.1 \pm 0.5^{* *}$ \\
\hline Area under glucose tolerance test curve ( $\mathrm{mmol} / \mathrm{L} / 90 \mathrm{~min})$ & $881 \pm 64$ & $1352 \pm 21^{*} \#$ & $1300 \pm 35^{*}$ & $1909 \pm 51^{*} \#^{\wedge}$ & $1401 \pm 67^{* *}$ \\
\hline HDL Cholesterol (mg/dl) & $21.5 \pm 0.3$ & $13.2 \pm 0.4 * \#$ & $19 \pm 1,0^{*}$ & $11.6 \pm 1,5^{*} \#^{\wedge}$ & $12.2 \pm 1.3^{*}$ \\
\hline High-sensitivity $\mathrm{C}$ reactive Protein $(\mathrm{mg} / \mathrm{dL})$ & $1.5 \pm 0.1$ & $3.5 \pm 0.0$ & $3.1 \pm 0.1$ & $4.5 \pm 0.1^{*} \#^{\wedge}$ & $3.1 \pm 0.3^{* *}$ \\
\hline \multicolumn{6}{|l|}{ Systolic blood pressure $(\mathrm{mmHg})$} \\
\hline Baseline & $105 \pm 3$ & $102 \pm 1.0$ & $103 \pm 1$ & $105 \pm 3$ & $105 \pm 2$ \\
\hline 6 weeks & $110 \pm 1.0$ & $129 \pm 2.0 *$ & $165 \pm 2 *$ & $172 \pm 3 * \#$ & $170 \pm 3^{*}$ \\
\hline 12 weeks & $112 \pm 1.3$ & $139 \pm 3.0 *$ & $178 \pm 1 * \#$ & $185 \pm 2 * \#^{\wedge}$ & $157 \pm 1.5^{* *}$ \\
\hline
\end{tabular}

Reagents: Unless otherwise noted, all reagents were Statistical and Data Analysis purchased from Sigma Chemical Co, MO USA.
A] was obtained from Millipore International Inc. (Amsterdam, Netherlands) (AB1604b), and goat anti-rat VCAM-1 (C-19) antibody was obtained from Santa Cruz Biotechnology Inc. (Santa Cruz USA) (sc-1504). Tissue sections were cut at a 3- $\mu \mathrm{m}$ thickness from paraffin-embedded blocks. The antibodies were diluted 1:1000. The primary incubations were carried out for 1 hour at $21-22^{\circ} \mathrm{C}$, followed by extensive six washes in PBS with Triton X-100 for 5 min each. The secondary antibodies, anti-rabbit IgG TR and anti-goat IgG FITC (Sigma-Aldrich), were diluted in PBS alone according to the manufacturer's instructions. The images were collected with Nikon EZ-C1 3.00 software on a Nikon Diaphot TMD microscope.

Measurement of the concentration of high-sensitive $C$ Reactive Protein (hs-CRP): The plasma HS-CRP concentrations were measured using a turbidimetric assay (Bayer Advia 1650, AG Leverkiusen). The data are expressed in $\mathrm{mg} / \mathrm{L}$.

Cytokine determination by "ChemiArray": The expression of the following cytokines was assessed using the Chemi Array system (rat antibody arrays) (Chemicon International, USA): neutrophil chemotactic cytokine 2 and 3 (CINC-2 and CINC-3), CX3CL1, monocyte chemotactic protein-1 (MCP-1), macrophage inflammatory protein-3 alpha (MIP-3 alpha), nerve growth factor beta (beta-NGF), tissue inhibitor of metalloproteinase-1 (TIMP1), vascular endothelial growth factor (VEGF), granulocytemacrophage colony-stimulating factor (GM-CSF), interferon gamma (INF- $\gamma$ ), interleukin 1 alpha and beta (IL-1 $\alpha$, IL-1 $\beta$ ), interleukin 4, 6 and 10 (IL-4, IL-6, IL-10) LIX, leptin, tumor necrosis factor alpha (TNF- $\alpha$ ). The procedures were carried out according to the manufacturer's instructions. Detection was performed with a chemiluminescence system and subsequent exposure to Kodak X-AR film (Eastman Kodak) for 5-30 s. The cytokines were distributed in the membranes according the map (Table 1).

purchased from Sigma Chemical Co, MO USA.

The data are expressed as the mean \pm SEM. The statistical significance of the comparisons between all groups was assessed 
by one-way ANOVA followed by the Bonferroni post-test. A twosided $p$ value of less than 0.05 was considered significant.

Results

\section{Long-term aldosterone inhibition by spironolactone improves metabolic indexes and blood pressure}

Chronic administration of fructose induced several alterations included in the cluster of risk factors that characterizes MS. The comparison between the HOMA index and the areas under the GTT curve indicated that the FFR and FFHR developed glucose intolerance, as demonstrated by the significantly increased HOMA index and area values compared to the control rats. Spironolactone did not produce significant changes within these variables (Table 1).

On the other hand, the animals in the FFR and FFHR groups also showed significant differences in the levels of triglycerides and HDL-cholesterol when compared to the controls (Table 1). Spironolactone treatment did not change metabolic variables. The SHR, FFR and FFHR groups also showed significant differences in the levels of hs-CRP when compared to the WKY group. The FFHR group showed higher hs-CRP levels than the other groups. Spironolactone induced partial reduction in CRP level in FFHR group (Table 1).

Table 1 also shows the time-course of the changes in SBP during the experimental period. By the sixth week, the SBP values of the FFHR and SHR groups were significantly increased compared to the control group, and there was an increase in pressure in the FFR group, which was lower but still significant.

The treatment with $S$ on the experimental groups was not able to reduce the values of SBP to normality although it showed a significant reduction of the same ones.

\section{Aldosterone inhibition results in the recovery of the oxidative status}

Table 2 shows that NAD(P)H-oxidase activity and the plasma TBARS concentration was significantly higher in the aortas of FFHR when compared to those from other groups. In addition, in the FFHR group, the arterial eNOS activity was significantly reduced, contributing to a decrease in the production and consequent bioavailability of nitric oxide (NO). Two different arterial tissues were used to demonstrate that oxidative stress is a systemic and non-tissue process.

Table 2: Oxidative stress and morphometric variables

\begin{tabular}{|c|c|c|c|c|c|}
\hline Variable & WKY & FFR & SHR & FFHR & FFHR+V \\
\hline NAD(P)H oxidase activity (counts/min/mg tissue) & $40.5 \pm 6$ & $133 \pm 5^{*}$ & $160 \pm 9.1^{*} \#$ & $297 \pm 9.1^{*} \#^{\wedge}$ & $42 \pm 9.1^{* \wedge * *}$ \\
\hline Arterial eNOS activity (dpm/mg/prot/min) & $85.0 \pm 2$ & $60.1 \pm 2.6^{*}$ & $80.0 \pm 2.1$ & $56.4 \pm 5.7^{*} \#^{\wedge}$ & $86.4 \pm 1.1^{* *}$ \\
\hline TBARS ( $\mu \mathrm{mol} / \mathrm{L})$ & $1 \pm 0.1$ & $2.2 \pm 0.1^{*}$ & $1.69 \pm 0.1^{*}$ & $2.8 \pm 0.1^{*} \#^{\wedge}$ & $1.03 \pm 0.6 \#^{\wedge * *}$ \\
\hline Relative heart weight $(\mathrm{mg} / 100 \mathrm{~g}$ body weight) & $225 \pm 4$ & $290 \pm 4^{*}$ & $330 \pm 1.8^{*} \#$ & $400 \pm 4^{*} \#^{\wedge}$ & $302 \pm 6^{* *}$ \\
\hline Myocardiocyte area $(\mu \mathrm{m} 2)$ & $1682 \pm 69$ & $2066 \pm 57^{*}$ & $2222 \pm 78^{*} \#$ & $3242 \pm 55^{*} \#^{\wedge}$ & $1788 \pm 34^{* *}$ \\
\hline Lumen/media relationship mesenteric arteries & $13.9 \pm 0.3$ & $10.2 \pm 0.5^{*}$ & $8.9 \pm 0.6^{*} \#$ & $8.45 \pm 0.2^{*} \#$ & $14.1 \pm 4^{* *}$ \\
\hline
\end{tabular}

Administration of Spironolactone effectively reduced superoxide production by reducing the activity of NAD(P)H oxidase and TBARS, and it was also able to normalize the eNOS activity (Table 2). Furthermore, most likely by inhibiting the activity of NAD(P)H oxidase, Spironolactone was also able to achieve these effects, normalizing the endothelial oxidative status (Table 2).

\section{Aldosterone inhibition modifies cardiac and vascular hypertrophy}

The RHW and myocardiocyte area was significantly higher in the FFR, SHR and FFHR groups than in the control rats, demonstrating myocardial hypertrophy in these experimental models (Table 2). Final body weight did not show significant differences between the experimental groups, citing the differences found in RHW to cardiac weight.

The FFHR group always displayed a significantly reduced $\mathrm{L} / \mathrm{M}$ when compared to the corresponding arteries from the WKY group; this result was also observed in the FFR and SHR groups. Chronic treatment with Spironolactone partially reduced myocardial hypertrophy and vascular remodeling in the FFHR model (Table 2).

\section{Spironolactone on vascular inflammation}

The expression of NF-kB and VCAM-1, two products that actively participates in vascular inflammation, is shown in Figure 1. Both molecules were detected by IHC. The expression of these molecules in the FFHR group increased significantly compared to the control group (W). The right panel shows a representative image of a WB for these proteins. The average optical density significantly increased in mesenteric artery homogenates from the FFHR and FFR groups compared to the controls. It can be observed that the distribution of the control load was similar for all groups.

In IHC images of the vascular wall, the FFHR group shows a large increase in NF-kB expression at the level of the EC and VSMC, and VCAM-1 is expressed at the sub-endothelial level. Spironolactone reduced the activation and nuclear translocation of NF- $\mathrm{kB}$ (p65 fraction) and VCAM-1 expression. This could be explained because in the FFHR group, nuclear factor NF$\kappa B$ production was more important due to the production of superoxide as result of the insulin-resistance status. This may also be a determining factor in the reduction of vascular remodeling, as previously shown. 


\section{Current Research in Diabetes \& Obesity Journal}
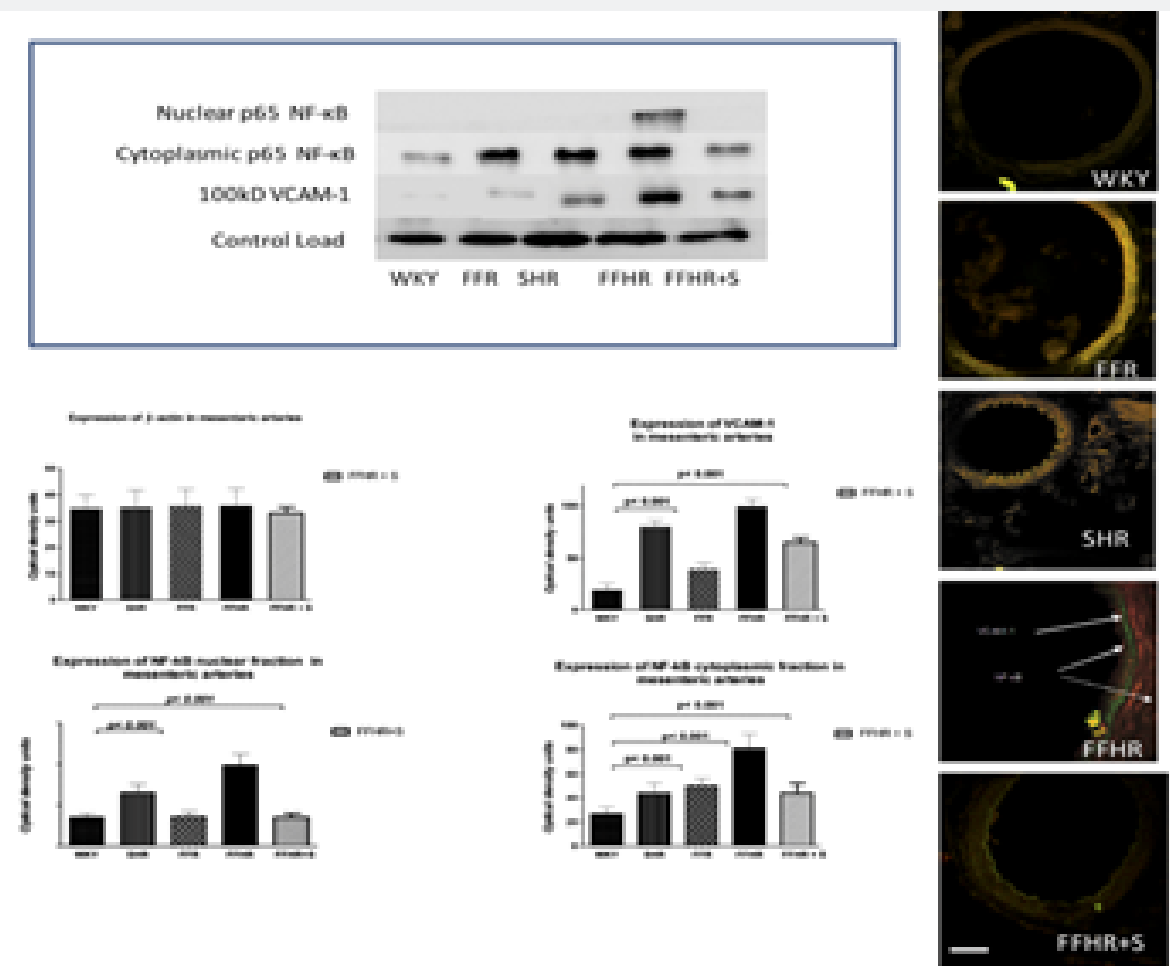

Figure 1: Cytoplasmatic and nuclear $\mathrm{p}-65$ fraction of NF-KB and VCAM-1 expression in mesenteric arteries detected using WB and IHC. The upper panel shows a representative WB probed with anti-VCAM-1-FITC and anti-p65-TRITC. The results represent the optical density of the bands for each group. The lower panel shows microphotographs of mesenteric tissue obtained using a laser ICM 600x.

\section{Aldosterone on activation of local cytokines}

In FFHR model, we observed a significant increase in the levels of several cytokines, including the following: CINC2, CINC3, VEGF, MIP-3, beta-NGF, VEGF, Leptin, TNF-alpha, INF-gamma and MCP-1 (Figures 2,3) (Table 3). This finding is the first evidence of the presence of local inflammation at the vascular level in an experimental model of insulin resistance, such as FFHR. This result shows the significant presence of pro-atherogenic cytokines, such as CINC2, CINC3, VEGF, Leptin, TNF-alpha, MCP1 and TIMP-1, as well as others whose role at the vascular level is unknown, such as MIP-3 and beta-NGF, INF-gamma and others with anti-atherogenic effects (Table 3 ).

\begin{tabular}{|c|c|c|c|c|c|c|c|c|}
\hline & A & B & C & D & E & $\mathbf{F}$ & G & H \\
\hline 1 & Positive & Positive & Negative & Negative & CINC-2 & CINC-3 & CNTF & Fractalkine \\
\hline 2 & Positive & Positive & Negative & Negative & CINC-2 & CINC-3 & CNTF & Fractalkine \\
\hline 3 & GM-CSF & INF- $\gamma$ & IL-1 $\alpha$ & IL- $1 \beta$ & IL-4 & IL-6 & IL-10 & LIX \\
\hline 4 & GM-CSF & INF- $\gamma$ & IL-1 $\alpha$ & IL- $1 \beta$ & IL-4 & IL-6 & IL-10 & LIX \\
\hline 5 & Leptin & MCP-1 & MIP- $3 \alpha$ & $\beta-N G F$ & TIMP-1 & TNF- $\alpha$ & VEGF & Blank \\
\hline 6 & Leptin & MCP-1 & MIP-3 $\alpha$ & $\beta$-NGF & TIMP-1 & TNF- $\alpha$ & VEGF & Blank \\
\hline 7 & Blank & Blank & Blank & Blank & Blank & Blank & Blank & Positive \\
\hline 8 & Blank & Blank & Blank & Blank & Blank & Blank & Blank & Positive \\
\hline
\end{tabular}

Figure 2: ChemiArray Rat Lysate Cytokine Antibody Array I Map. 


\section{Current Research in Diabetes \& Obesity Journal}

Table 3: Cytokine release profiles on different experimental models.

\begin{tabular}{|c|c|c|c|c|c|c|}
\hline \multirow{2}{*}{ Cytokinea } & \multirow{2}{*}{ Relative levelsb } & \multirow{2}{*}{ Array Locationc } & \multicolumn{4}{|c|}{ Fold increase for control group (WKY)d } \\
\hline & & & SHR & FFR & FFHR & FFHR+V \\
\hline CINC-2 & $\mathrm{H}$ & E1-2 & 1.1 & 1.5 & 2.72 & 2.75 \\
\hline CINC-3 & $\mathrm{H}$ & F1-2 & 1.74 & 1.2 & 2.34 & 2.6 \\
\hline CNTF & - & G1-2 & $\sim$ & $\sim$ & $\sim$ & $\sim$ \\
\hline Fractalkine & - & $\mathrm{H} 1-2$ & $\sim$ & $\sim$ & $\sim$ & $\sim$ \\
\hline GM-CSF & - & A4-5 & $\sim$ & $\sim$ & $\sim$ & $\sim$ \\
\hline INF- $\gamma$ & $\mathrm{H}$ & B3-4 & 5 & 4.2 & 6.1 & 5.8 \\
\hline IL-1 $\alpha$ & - & C3-4 & $\sim$ & $\sim$ & $\sim$ & $\sim$ \\
\hline IL-1 $1 \beta$ & - & D3-4 & $\sim$ & $\sim$ & $\sim$ & $\sim$ \\
\hline IL-4 & - & E3-4 & $\sim$ & $\sim$ & $\sim$ & $\sim$ \\
\hline IL-6 & - & F3-4 & $\sim$ & $\sim$ & $\sim$ & $\sim$ \\
\hline IL-10 & - & G3-4 & $\sim$ & $\sim$ & $\sim$ & $\sim$ \\
\hline LIX & - & H3-4 & $\sim$ & $\sim$ & $\sim$ & $\sim$ \\
\hline Leptin & $\mathrm{H}$ & A5-6 & 1.06 & 1.23 & 2.5 & 1.07 \\
\hline MCP-1 & $\mathrm{H}$ & B5-6 & 1.05 & $\mathrm{NC}$ & 4 & 1.02 \\
\hline MIP- $3 \alpha$ & $\mathrm{H}$ & C5-6 & 1.18 & 1.34 & 4.01 & 3.8 \\
\hline$\beta$-NGF & $\mathrm{H}$ & D5-6 & 2.45 & 2.5 & 3.2 & 2.53 \\
\hline TIMP-1 & $\mathrm{H}$ & E5-6 & 2.87 & 1.55 & 2.5 & $\sim$ \\
\hline TNF- $\alpha$ & $\mathrm{H}$ & F5-6 & 3.12 & 1.13 & 3.55 & 1.02 \\
\hline VEGF & $\mathrm{H}$ & G5-6 & 2.65 & $\mathrm{NC}$ & 3.15 & $\sim$ \\
\hline
\end{tabular}

a: Name of cytokine; b: Relative levels undetectable; H: High: L: Low; c: See Figure 3 for the location of the duplicate spots in the matrix

d: When the control " " symbol was used to indicate an approximation of zero, the values indicate the fold increase vs. WKY (control group). $\mathrm{NC}$, no change (less than or equal to the fold change in the WKY group)

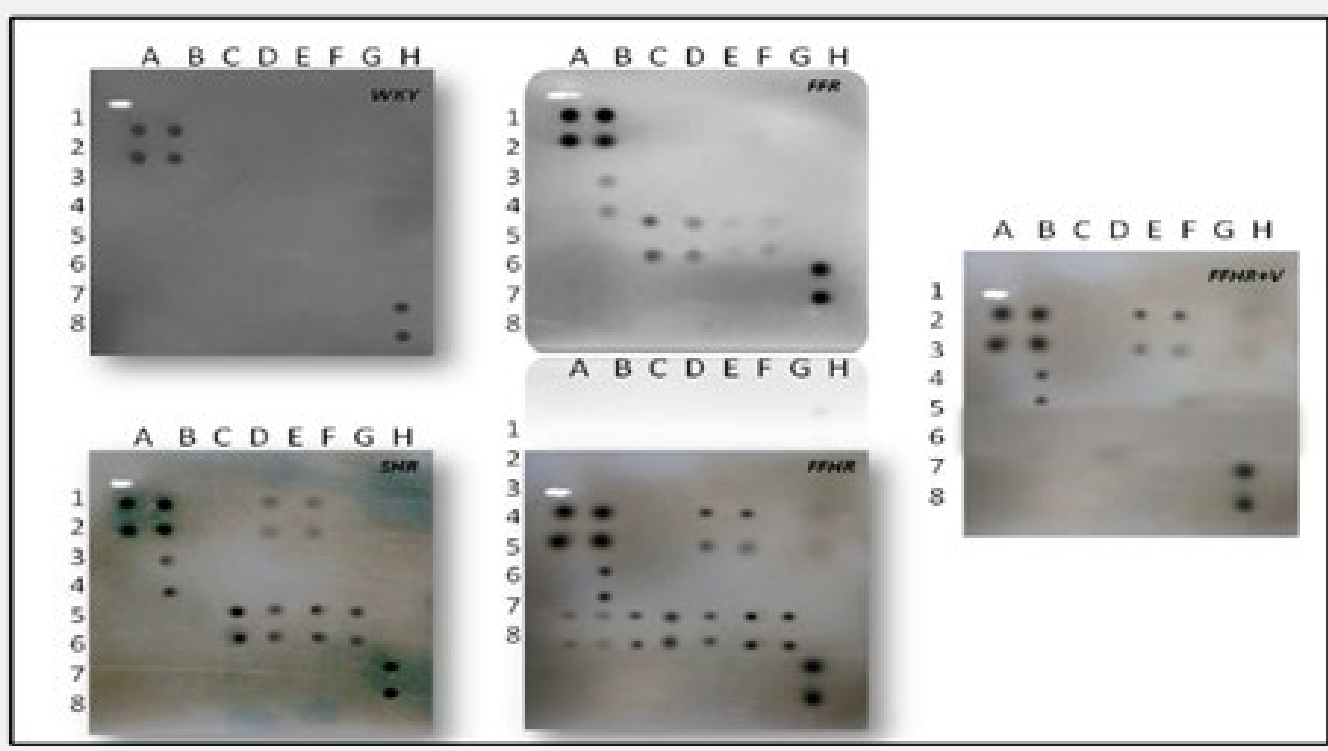

Figure 3: Detection of cytokines on membrane antibody arrays by chemiluminescence. Duplicate spots in the following locations represent each cytokine. See Figure 1. The average net light intensity for each pair of cytokine spots detected based on ray-scale levels using US NIH Image software ver 1.66 .

Cytokines names: Neutrophil chemotactic cytokine 2 and 3 (CINC-2 and CINC-3), ciliary neurotrophic factor (CNFT), monocyte chemotactic protein-1 (MCP-1), inflammatory protein macrophage-3 alpha (MIP-3 alpha), nerve growth factor beta (beta-NGF), tissue inhibitor of metalloproteinase-1 (TIMP-1) and vascular endothelial growth factor (VEGF), granulocyte colony stimulating factor, macrophage (GM-

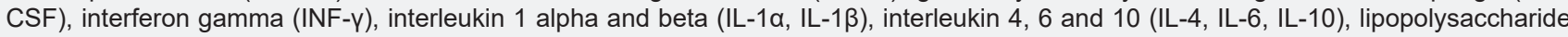
induced CXC chemokine (LIX or CXCL5), leptin, tumor necrosis factor alpha (TNF- $\alpha$ ). 
Chronic treatment with Spironolactone returned the expression levels of pro-atherogenic cytokines, including VEGF, TIMP-1 and MCP-1, to control values, and Spironolactone administration significantly reduced MIP-3alpha and TNF-alpha, demonstrating the important role that the Mineralocorticoid Receptor (MR) plays in vascular inflammation in this experimental model (Table 3).

\section{Discussion}

The present study demonstrates that vascular inflammation and remodeling in FFHR is attenuated by MR antagonism through processes associated with reduced vascular oxidative stress and cytokines responses. Our data provide additional information on mechanisms whereby MR antagonists, such as spironolactone, protect against diabetes-associated vasculopathy and further support the idea that MR antagonists have beneficial vascular effects in DM2-associated conditions (Figure 3).

The FFHR experimental model presents hypertension, dyslipidemia, insulin resistance, vascular and cardiac remodeling, inflammation demonstrated by increased hsCRP and vascular inflammation due to increased expression of NF-kB, VCAM-1 and pro-atherogenic cytokines. The increased expression of VCAM-1 is a marker of vascular inflammation, vascular permeability and endothelial dysfunction [32-34]. The inflammatory process was previously identified in this experimental model [35-37].

Obesity and DM2 are closely related with high aldosterone levels, and MR antagonist therapy has shown positive effects on cardiovascular complications associated with these diseases [38-40]. Spironolactone treatment produces beneficial cardiovascular effects independently of a reduction of aldosterone levels $[41,42]$.
In Figure 4 we show the mechanisms by which MR blockade through genomic or non-genomic mechanisms, results in an increase in NADPH oxidase activity, increasing the ROS values. This activates the transcription of different cellular mediators such as NF-kB or AP-1, activating the inflammatory cascade, which in our experimental model assumes that it starts with IL- 6 and from this VCAM-1, MCP-1 and TNF-alpha generating remodeling of the extracellular matrix and vascular inflammation.

Also, aldosterone plays a positive role to enhance insulin levels, as well as to induce insulin resistance $[43,44]$. Rats treated with aldosterone present insulin resistance, by mechanisms that involve MR receptor activation and oxidative stress. We have recently shown that FFHR treated with the MR antagonist Spironolactone have improved metabolic and cardiovascular profile. In the present study, Spironolactone treatment reduced, but not normalized insulin levels. Spironolactone treatment did not influence blood pressure, in line with previous reports [3745].

Vascular dysfunction in diabetic patients is ameliorated by treatment with MR antagonists, indicating that MR blockade may prevent or revert cardiovascular disease in patients with DM2 [25]. In arterial hypertension and heart failure, aldosterone has been shown to mediate maladaptive changes in the cardiovascular system by mechanisms that involve Nox activation, oxidative stress, reduced NO bioavailability and ultimately, vascular dysfunction [46-50]. In these conditions, MR blockade reduces cardiac inflammation, oxidative stress, fibrosis, remodeling, hypertrophy, and improves cardiac and vascular function $[40-42,49]$.

Findings from our study demonstrate that treatment with a MR antagonist abrogates vascular dysfunction and remodeling.

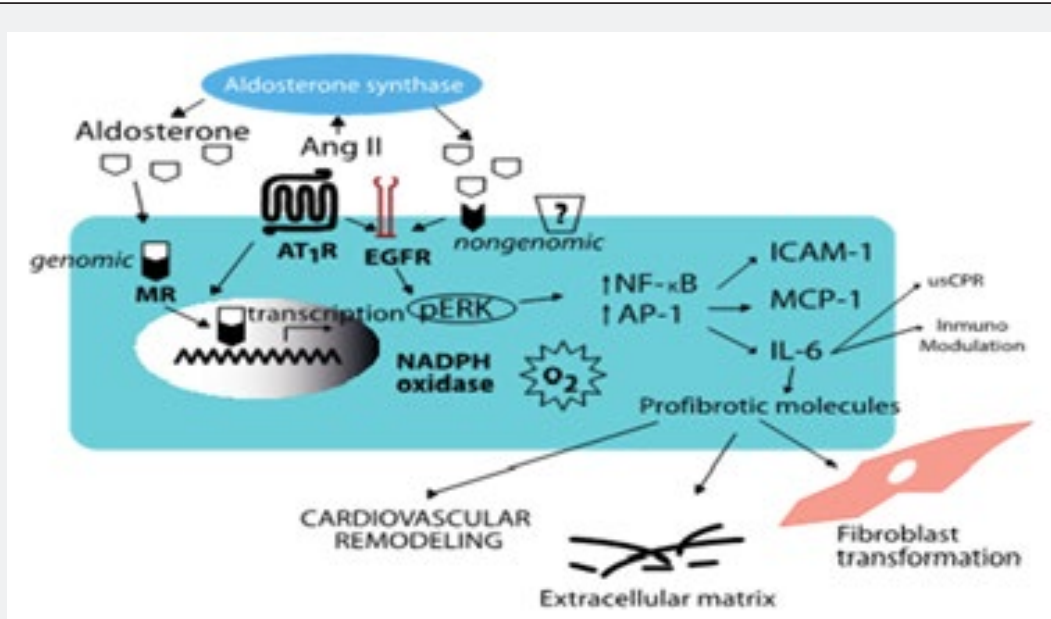

Figure 4: Cartoon of mechanisms of aldosterone-induced vascular inflammation: aldosterone acting at the MR, affects the transcription of proinflamaatory genes. Aldosterone also activates NADPH oxidases to produce reactive oxygen species. Ang II increases MR-dependent transcription in VSMCs way its AT1 receptor. Aldosterone and Ang II phosphorylate ERK $1 / 2$ through genomic and non-genomic pathways. Increased oxidative stress and activation of ERK result in the expression of proinflammatory transcription factors, adhesion molecules and MCP-1 or IL-6. (Adapted Brown N in Aldosterone and Vascular Inflammation. Hypertension 2008; 51:161-167). 


\section{Current Research in Diabetes \& Obesity Journal}

Aldosterone also increases ROS production via activation of NADPH oxidase (Nox) isoforms. Whereas aldosterone administration increases vascular oxidative status, therapy with MR antagonists abrogates oxidative stress [38-42], suggesting that aldosterone-induced ROS formation depends on MR receptor. It has recently shown that aortae from $\mathrm{db} / \mathrm{db}$ mice exhibit enhanced Nox expression and activity [12] and that MR antagonist therapy reduces oxidative stress possibly via modulation of Nox enzymes-dependent mechanisms [49] (Figure 4).

\section{Conclusion}

In conclusion, our data demonstrate that spironolactone, a MR antagonist, improves vascular function by reducing oxidative stress, upregulating antioxidant systems and modulating inflammatory response. These data imply a role for aldosterone in vascular dysfunction and suggest that spironolactone may have vasoprotective effects in diabetes-associated cardiovascular complications.

\section{References}

1. MacLeod AB, Vasdev S, Smeda JS (1997) The role of blood pressure and aldosterone in the production of hemorrhagic stroke in captopriltreated hypertensive rats. Stroke 28(9): 1821-1828.

2. Rocha R, Chander PN, Khanna K, Zuckerman A, Stier CT (1998) Mineralcorticoid blockade reduces vascular injury in stroke-prone hypertensive rats. Hypertension 31(1): 451-458.

3. Fiebeler A, Schmidt F, Müller DN, Park JK, Dechend R, et al. (2001) Mineralcorticoid receptor affects AP-1 and nuclear factor-kB activation in angiotensin II-induced cardiac injury. Hypertension 37(2): 787-793.

4. AA Herrada, C Campino, CA Amador, LF Michea, CE Fardella, et al. (2011) Aldosterone as a modulator of immunity: implications in the organ damage. J Hypertens 29(9): 1684-1692.

5. Munoz-Durango, MF Barake, NA Letelier, C Campino, CE Fardella, et al. (2013) Immune system alterations by aldosterone during hypertension: from clinical observations to genomic and non-genomic mechanisms leading to vascular damage. Curr Mol Med 13(6): 10351046.

6. S Gra e-Faure, C Leveque, M Vasse, C Soria, V Norris, et al. (1999) Effects of glucocorticoids and mineralocorticoids on proliferation and maturation of human peripheral blood stem cells. Am J Hematol 62(2): 65-73.

7. Rossignol J, Menard R, Fay F, Gustafsson B, Pitt F, et al. (2011) Eplerenone survival bene ts in heart failure patients post-myocardial infarction are independent from its diuretic and potassium-sparing effects: insights from an EPHESUS (Eplerenone Post-Acute Myocardial Infarction Heart Failure Efficacy and Survival Study) substudy. J Am Coll Cardiol 58(19): 1958-1966

8. Keidar S, Hayek T, Kaplan M, Pavlotzky E, Hamoud S, et al. (2003) Effect of eplerenone, a selective aldosterone blocker, on blood pressure, serum and macrophage oxidative stress, and atherosclerosis in apolipoprotein E-deficient mice. Journal of Cardiovascular Pharmacology 41(6): 955-963.

9. Caprio M, Newfell BG, LaSala A, Baur W, Fabbri A, et al. (2008) Functional Mineralocorticoid Receptors in Human Vascular Endothelial Cells Regulate ICAM-1 Expression and Promote Leukocyte Adhesion. Circulation Research 102(11): 1359-1367.
10. Jaffe IZ, Mendelsohn ME (2005) Angiotensin II and aldosterone regulate gene transcription via functional mineralocortocoid receptors in human coronary artery smooth muscle cells. Circ Res 96(6): 643650 .

11. Jaffe IZ, Tintut Y, Newfell BG, Demer LL, Mendelsohn ME (2007) Mineralocorticoid receptor activation promotes vascular cell calcification. Arterioscler Thromb Vasc Biol 27(4): 799-805.

12. Newfell BG, Iyer LK, Mohammad NN (2011) Aldosterone Regulates Vascular Gene Transcription via Oxidative Stress-Dependent And -Independent Pathways. Arterioscler Thromb Vasc Biol 31: 1871-1880.

13. McCurley A, Jaffe IZ (2012) Mineralocorticoid Receptors in Vascular Function and Disease. Mol Cell Endocrinol 350(2): 256-265.

14. McCurley A, Pires PW, Bender SB, Aronovitz M, Zhao MJ, et al. (2012) Direct Regulation of Blood Pressure by Smooth Muscle Cell Mineralocorticoid Receptors. Nature Medicine 18(9): 1429-1433.

15. Pruthi D, McCurley A, Aronovitz M, Galayda C, Karumanchi SA, et al. (2013) Aldosterone promotes vascular remodeling by direct effects on smooth muscle cell mineralocorticoid receptors. Arterioscler Thromb Vasc Biol 34(2): 355-364.

16. Sica A, Mantovani A (2012) Macrophage plasticity and polarization: in vivo veritas. J Clin Invest 122(3): 787-795.

17. Stumpo R, Kauer M, Martin S, Kolb H (2003) IL-10 induces gene expression in macrophages: partial overlap with IL-5 but not with IL-4 induced genes. Cytokine 24(1-2): 46-56.

18. Gratchev A, Kzhyshkowska J, Kannookadan S, Ochsenreiter M, Popova A, et al. (2008) Activation of a TGF- $\beta$-specific multistep gene expression program in mature macrophages requires glucocorticoidmediated surface expression of TGF- $\beta$ receptor II. J Immunol 180(10): 6553-6565.

19. Amador CA, Barrientos V, Peña J, Herrada AA, González M, et al. (2014) Spironolactone decreases DOCA-salt-induced organ damage by blocking the activation of T helper 17 and the downregulation of regulatory T lymphocytes. Hypertension 63(4): 797-803.

20. Pitt B, Zannad F, Remme WJ, Cody R, Castaigne A, et al. (1999) The effect of spironolactone on morbidity and mortality in patients with severe heart failure. Randomized aldactone evaluation study investigators. $\mathrm{N}$ Engl J Med 341(10): 709-717.

21. Renna NF, Lembo C, Diez E, Miatello R (2013) Role of renin-angiotensin system and oxidative stress on vascular inflammation in insulin resistence model. Int J Hypertens.

22. Valerio A, Cardile A, Cozzi V, Bracale R, Tedesco L, et al. (2006) TNF- $\alpha$ downregulates eNOS expression and mitochondrial biogenesis in fat and muscle of obese rodents. J Clin Invest 116(10): 2791-2798.

23. Vomhof-DeKrey EE, Picklo MJ (2012) NAD(P)H:quinone oxidoreductase 1 activity reduces hypertrophy in 3T3-L1 adipocytes. Free Radic Biol Med 53(4): 690-700.

24. Heitzer T, Krohn K, Albers S, Meinertz T (2000) Tetrahydrobiopterin improves endothelium-dependent vasodilation by increasing nitric oxide activity in patients with Type II diabetes mellitus. Diabetologia 43(11): 1435-1438.

25. Bruder-Nascimento T, da Silva MA, Tostes RC (2014) The involvement of aldosterone on vascular insulin resistance: implications in obesity and type 2 diabetes. Diabetol Metab Syndr 6(1): 90.

26. Hollenberg NK, Stevanovic R, Agarwal A, Lansang MC, Price DA, et al. (2004) Plasma aldosterone concentration in the patient with diabetes mellitus. Kidney Int 65(4): 1435-1439.

27. Toda N, Nakanishi S, Tanabe S (2013) Aldosterone affects blood flow and vascular tone regulated by endothelium-derived NO: therapeutic implications. Br J Pharmacol 168(3): 519-553. 
28. Renna, N. Lembo C, Diez E, Miatello R (2012) Vascular repair by endothelial progenitor cells in an experimental model of metabolic syndrome, in Handbook on Metabolic Syndrome: Classification, Risk Factors and Health Impact, C.M.L.G.a.P.A.P. Gonzalez, Hardcover USA.

29. Keaney JF, Gaziano JM, Xu B, Frei B, Curran-Celentano J, et al. (1993) Dietary Antioxidants Preserve Endothelium-Dependent Vessel Relaxation in Cholesterol-Fed Rabbits. Proc Natl Acad Sci U S A 90(24): 11880-11884.

30. Furchgott RF, Zawadzki JV (1980) The obligatory role of endothelial cells in the relaxation of arterial smooth muscle by acetylcholine. Nature 288(5789): 373-376.

31. Ignarro, L Byrns R, Buga G, Wood K (1987) Endothelium-derived relaxing factor from pulmonary artery and vein possesses pharmacologic and chemical properties identical to those of nitric oxide radical. Circ Res 61(6): 866-879.

32. Renna, N., Vazquez MA, Lama MC, González ES, Miatello RM (2009) Effect of chronic aspirin administration on an experimental model of metabolic syndrome. Clin Exp Pharmacol Physiol 36(2): 162-168.

33. Fleming I, Busse R (1999) Signal transduction of eNOS activation. Cardiovascular Research 43(3): 532-541.

34. Michel JB, Feron O, Sase K, Prabhakar P, Michel T (1997) Caveolin versus Calmodulin. Journal of Biological Chemistry 272(41): $25907-$ 25912.

35. Peairs AD, Rankin JW, Lee YW (2011) Effects of acute ingestion of different fats on oxidative stress and inflammation in overweight and obese adults. Nutr J 10: 122.

36. Dong A, Shen J, Zeng M, Campochiaro PA (2011) Vascular cell-adhesion molecule-1 plays a central role in the proangiogenic effects of oxidative stress. Proc Natl Acad Sci U S A 108(35): 14614-14619.

37. Renna NF, de Las Heras N, Miatello RM (2013) Pathophysiology of vascular remodeling in hypertension. Int J Hypertens 2013: 808353.

38. Renna NF, Diez EA, Miatello RM (2014) Effects of dipeptidyl-peptidase 4 inhibitor about vascular inflammation in a metabolic syndrome model. PLoS One 9(9): e106563.

39. Renna NF, Diez ER, Lembo C, Miatello RM (2013) Role of Cox-2 in vascular inflammation: an experimental model of metabolic syndrome. Mediators Inflamm 2013: 513251
40. Renna NF, Vazquez MA, Lama MC, González ES, Miatello RM (2009) Effect of chronic aspirin administration on an experimental model of metabolic syndrome. Clin Exp Pharmacol Physiol 36(2): 162-168.

41. Briones AM, Nguyen Dinh Cat A, Callera GE, Yogi A, Burger D, et al. (2012) Adipocytes produce aldosterone through calcineurindependent signaling pathways: implications in diabetes mellitusassociated obesity and vascular dysfunction. Hypertension 59: 10691078.

42. Silva MA, Cau SB, Lopes RA, Manzato CP, Neves KB, et al. (2015) Mineralocorticoid receptor blockade prevents vascular remodelling in a rodent model of type 2 diabetes mellitus. Clin Sci (Lond) 129(7): 533-545.

43. Mejía-Vilet JM, Ramírez V, Cruz C, Uribe N, Gamba G, et al. (2007) Renal ischemia-reperfusion injury is prevented by the mineralocorticoid receptor blocker spironolactone. Am J Physiol Renal Physiol 293: F78-F86.

44. Resch M, Schmid P, Amann K, Fredersdorf S, Weil J, et al. (2011) Eplerenone prevents salt-induced vascular stiffness in Zucker diabetic fatty rats: a preliminary report. Cardiovasc Diabetol 10: 94.

45. Patel BM, Mehta AA (2012) Aldosterone and angiotensin: role in diabetes and cardiovascular diseases. Eur J Pharmacol 697: 1-12.

46. Garg R, Rao AD, Baimas-George M, Hurwitz S, Foster C, et al. (2015) Mineralocorticoid receptor blockade improves coronary microvascular function in individuals with type 2 diabetes. Diabetes 64(1): 236-242.

47. Callera GE, Touyz RM, Tostes RC, Yogi A, He Y, et al. (2005) Aldosterone activates vascular p38MAP kinase and NADPH oxidase via c-Src. Hypertension 45(4): 773-779.

48. Calhoun DA (2006) Aldosterone and cardiovascular disease: smoke and fire. Circulation 114(24): 2572-2574

49. Virdis A, Neves MF, Amiri F, Viel E, Touyz RM, et al. (2002) Spironolactone improves angiotensin-induced vascular changes and oxidative stress. Hypertension 40(4): 504-510.

50. Brown NJ (2013) Contribution of aldosterone to cardiovascular and renal inflammation and fibrosis. Nat Rev Nephrol 9: 459-469.

Your next submission with Juniper Publishers
will reach you the below assets
- Quality Editorial service
- Swift Peer Review
- Reprints availability
- E-prints Service
- Manuscript Podcast for convenient understanding
- Global attainment for your research
- Manuscript accessibility in different formats
( Pdf, E-pub, Full Text, Audio)
- Unceasing customer service
Track the below URL for one-step submission
https://juniperpublishers.com/online-submission.php

